\title{
Ureaplasma urealyticum in the urethra of healthy
} men

\author{
J VIARENGO, $†$ F HEBRANT, * AND P PIOT + \\ From the *Unit of Biometry and the + Bacteriology Laboratory, Institute of Tropical Medicine, Antwerp, \\ Belgium
}

SUMMARY Nineteen healthy married white men had samples of first-voided urine cultured for Ureaplasma urealyticum at weekly intervals for 17 consecutive weeks. Of these, $63 \%$ harboured $U$ urealyticum in their urine on at least one occasion; in $40 \%$ of the men with positive culture results ureaplasmas were isolated from $90 \%$ of samples. Those men whose specimens were frequently culture-positive had notably higher titres for $U$ urealyticum than those whose specimens were less frequently positive. There was no significant correlation between the number of leucocytes in the urinary sediment and the amount of $U$ urealyticum in the corresponding urine specimens, although ureaplasma-positive urine specimens tended to contain slightly more leucocytes than ureaplasma-negative samples. Fourfold or higher rises in titre of $U$ urealyticum in urine samples was not associated with urethral signs or symptoms. One man with a presumably primary infection developed dysuria. Sixty-five strains of $U$ urealyticum were serotyped, with types 2 and 3 predominating; the serotype found in each patient was fairly constant.

\section{Introduction}

The most convincing evidence that Ureaplasma urealyticum is associated with nongonococcal urethritis (NGU) has been given by Bowie and coworkers.' Among men experiencing a first episode of urethritis $U$ urealyticum was recovered more often and in greater numbers from chlamydia-negative cases of NGU than from chlamydia-positive cases or from men without urethritis. Further support for a pathogenic role for $U$ urealyticum has come from treatment studies ${ }^{2-4}$ and from intraurethral inoculation of the organism into man. ${ }^{56}$

Nevertheless the question why $U$ urealyticum is found in the urethra of a notable proportion of men without urethritis still remains unanswered; although the above studies suggest that $U$ urealyticum is a pathogen in the urethra, they do not prove that it is a cause of NGU.

In the present study of $U$ urealyticum in the urethra of healthy monogamous men, our aim was to try to establish: (a) whether $U$ urealyticum is a stable, permanent inhabitant of healthy sexually active men

Address for reprints: Dr P Piot, Institute of Tropical Medicine, Nationalestraat 155, B-2000 Antwerp, Belgium

Received for publication 5 September 1979 or part of a transient urethral flora; and (b) whether or not there is any pronounced variation in the quantity of $U$ urealyticum recovered from an individual over a period of time and if this variation is associated with any urethral signs and symptoms.

\section{Patients and methods}

STUDY POPULATION

Nineteen white men (aged 21-62 years) working at the Institute of Tropical Medicine in Antwerp were included in the study. They all claimed to be sexually active and were married; they denied a previous history of urethritis and were free of any infectious urinary tract disease as assessed by urine cultures for Gram-negative and Gram-positive bacteria.

\section{CULTURAL TECHNIQUE}

The first $10 \mathrm{ml}$ of each man's overnight urine was collected weekly on the same day (Monday) for 17 consecutive weeks. A $0 \cdot 2-\mathrm{ml}$ quantity of fresh urine was cultured quantitatively in serial twofold or tenfold dilutions in bromothymolblue broth ${ }^{7}$ (the former during the first 12 weeks of the study, the latter during the last five weeks). Colonial counts were performed on A7 $\mathrm{agar}^{8}$ in tenfold dilutions of 
fresh urine. One drop (approximately $0.02 \mathrm{ml}$ ) of the pellet of centrifuged urine (at $400 \times g$ for 10 minutes) was also inoculated on to A7 medium and another drop was examined for the presence of leucocytes at $\times 400$ magnification. All isolates were stored at $-70^{\circ} \mathrm{C}$ in fetal calf serum without cloning.

\section{SEROTYPING}

Antisera to the eight serotypes of $U$ urealyticum ${ }^{9}$ were raised in rabbits as described by Shepard..$^{10}$ The growth inhibition (GI) test was performed as reported earlier, ${ }^{11}$ except that A7 agar was used as the growth medium. The indirect immunoflourescence (IF) test using unfixed colonies on agar has already been described. ${ }^{11}$ Antisera for the IF test were used at the following dilutions: $1 / 160$ (types $1,4,5$, and 8 ); 1/320 (type 7); and 1/640 (types 2, 3, and 6). Cultures were considered to be mixed when only part of the colonies on an agar block fluoresced with a particular antiserum; on other blocks from the same isolate some colonies strongly fluoresced with a different antiserum (an agar block in the test usually contained five colonies).

\section{STATISTICAL METHODS}

The statistical analyses were performed on the $\log _{10}$ of the first negative dilution for the titre and on the $\log _{10}$ of the number of leucocytes (plus 1 to avoid zero values to be transformed in log, this tranformation being the classical one to normalise the frequency data).

A one-way analysis of variance was used on the mean titres. The association between negative and positive and the number of leucocytes $(\leqslant 5, \geqslant 5)$ was tested by the $\chi^{2}$ test for a $2 \times 2$ contingency table with Yates's correction.

\section{Results}

\section{CULTURES}

The 19 men were divided into four groups (A, B, C, and $\mathrm{D}$ ) according to the rate of positive isolation. Twelve $(63 \%)$ of them harboured $U$ urealyticum in the urethra on at least one occasion, and in five of the culture-positive men ureaplasmas were isolated from more than $70 \%$ of the weekly specimens (table I). During the last five weeks of the study, five men in group A and one in group B had $>10^{3}$ colourchanging units (ccu) of $U$ urealyticum in their urine on at least one occasion.

\section{GEOMETRIC MEAN TITRES}

The variation in the individual geometric mean titres with their 0.95 confidence interval for the first 12 weeks of the study is shown in fig 1 . Values could fluctuate in the same patient and low values could immediately follow high values. Thus, those patients whose specimens frequently gave positive results had higher titres than those whose specimens less frequently gave positive results. A one-way analysis of variance showed a significant difference between the individual mean titre $(F=7 \cdot 045$ with 11 and 12 degrees of freedom; $\mathrm{P}<0 \cdot 01)$. A decomposition of the factorial sum of squares showed that this result was mostly due to the difference between group A

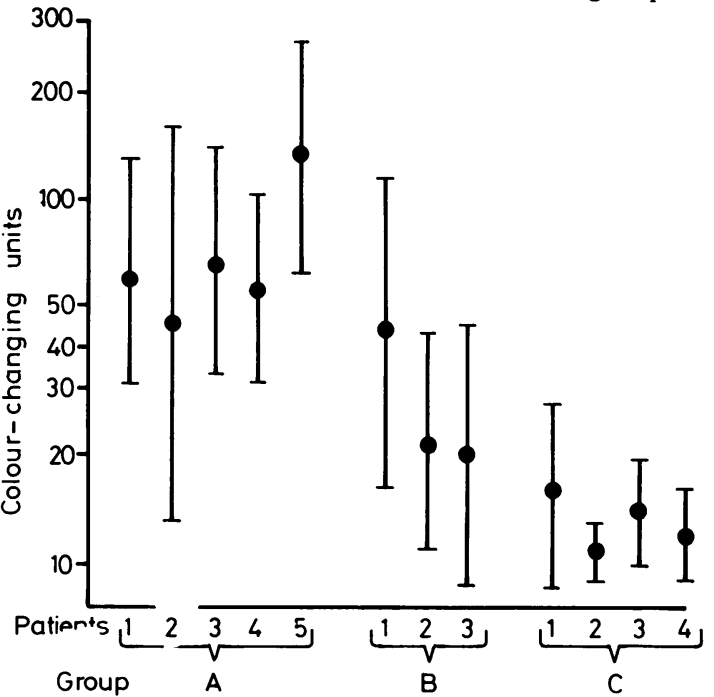

FIG 1 Variation in individual geometric mean titres (colour-changing units) (with their 0.95 confidence intervals) of Ureaplasma urealyticum of patients grouped $(A, B, C$, and $D)$ according to their positive isolation rate.

TABLE I Isolation rate, number of leucocytes, and titre of Ureaplasma urealyticum from specimens of first-voided urine from 19 men followed weekly for 17 weeks

\begin{tabular}{lllll}
\hline Patient group & $\begin{array}{l}\text { \% Positive isolation } \\
\text { (over 17 weeks) }\end{array}$ & No of patients & $\begin{array}{l}\text { Geometric mean } \\
\text { titre (ccu) }\end{array}$ \\
\hline A & 270 & 5 & $65 \cdot 6$ & $\begin{array}{l}\text { Geometric mean } \\
\text { No of leucocytes }\end{array}$ \\
B & $35-69$ & 3 & $26 \cdot 7$ & $3 \cdot 6$ \\
C & $<35$ & 4 & $12 \cdot 8$ & $1 \cdot 6$ \\
D & 0 & 7 & $2 \cdot 0$ & $1 \cdot 3$ \\
\hline
\end{tabular}

$\mathrm{ccu}=$ Colour-changing units 
and groups B and C $(73 \%$ of the factorial sum of squares).

\section{NUMBER OF LEUCOCYTES}

The individual geometric mean numbers of leucocytes, with their 0.95 confidence interval, in culture-positive and culture-negative specimens (fig 2) showed great individual variation; there was no significant association between the number of leucocytes in the urinary sediment and the titre of $U$ urealyticum present in the corresponding urine samples $\left(\chi_{1}^{2}=0 \cdot 782, P=0 \cdot 40\right)$, although culture-

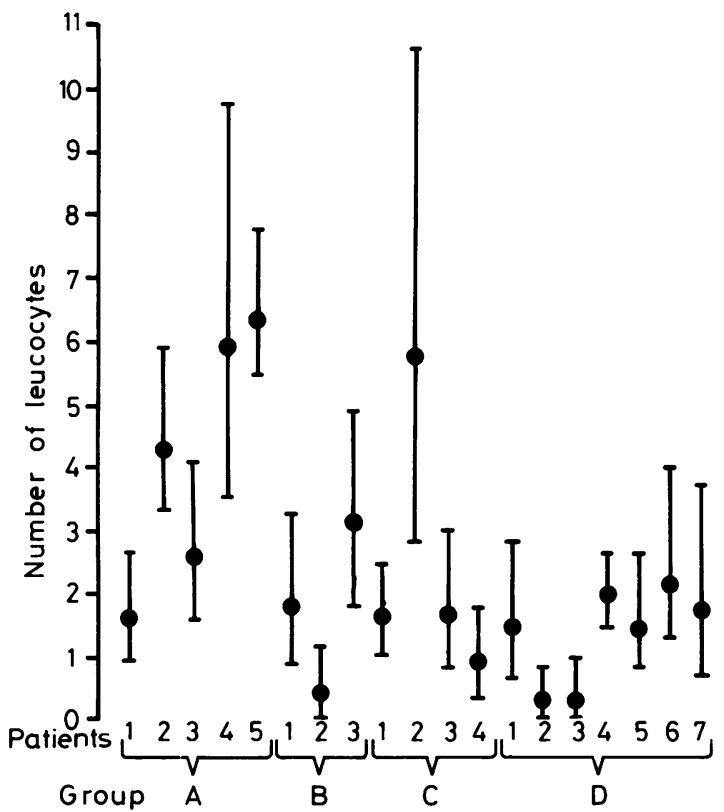

FIG 2 Individual geometric mean numbers of leucocytes with their 0.95 confidence interval in ureaplasma-positive and ureaplasma-negative specimens of patients in each group $(A, B, C$, and $D)$. (Confidence intervals were computed using the log of the numbers of leucocytes and transformed back to antilog for the figure.) positive urine specimens tended to contain slightly more leucocytes than culture-negative specimens (mean of 3-4 leucocytes and 1-2 leucocytes respectively per microscopic field $\times 400$ ). All samples contained less than 13 leucocytes per high-power field (HPF).

\section{SEROTYPES}

Sixty-five strains isolated from nine men were serotyped by IF and 37 of these also by the GI test. The overall agreement between both tests was $81 \%$, the discrepancy being caused exclusively by the inability of the GI test to type certain isolates. Table II shows the results obtained with the IF test. The predominant serotypes were 2 and 3 , occurring in four and five men respectively. One person harboured type 7 only. Types 4, 5, and 6 were found occasionally in combination with types 2 and 3 . Mixed isolates were found on at least one occasion in seven of nine men. The serotype present in each man was fairly constant, and in all but one case the same type was found in the first and the last culture tested.

A presumably primary infection with $U$ urealyticum was diagnosed in patient 3 (table II), who had been culture-negative for the four preceeding weeks. Five days after extramarital intercourse $U$ urealyticum serotype 3 was recovered from his first-voided urine specimen at a titre of $1 / 160 \mathrm{ccu}$ and associated with 11 leucocytes per HPF $\times 400$. For 10 days he complained of mild dysuria without discharge or any other signs of urethritis such as urinary mucous threads. This man remained infected with ureaplasmas for the remainder of the study, with titres varying between $1 / 20$ and $1 / 10^{5} \mathrm{ccu}$ and leucocytes between 4 and 11 per HPF $\times 400$. No other patients had any symptoms or signs of urethritis.

\section{Discussion}

$U$ urealyticum (notably types 2 and 3 ) appeared to be a part of the permanent urethral flora in at least one-

TABLE II Serotypes of Ureaplasma urealyticum isolated from 12 samples of first-voided urine from eight healthy men

\begin{tabular}{|c|c|c|c|c|c|c|c|c|c|c|c|c|}
\hline \multirow[b]{2}{*}{ Patient No } & \multicolumn{12}{|c|}{ Serotypes per suinpie No } \\
\hline & 1 & 2 & 3 & 4 & 5 & 6 & 7 & 8 & 9 & 10 & $I I$ & 12 \\
\hline $\begin{array}{l}1 \\
2 \\
3 \\
4 \\
5 \\
6 \\
7 \\
8\end{array}$ & $\begin{array}{l}3 \\
2,7 \\
* \\
3,6 \\
2 \\
2 \\
\text { NT } \\
*\end{array}$ & $\begin{array}{l}3 \\
2,3 \\
* \\
* \\
2 \\
2 \\
2,6\end{array}$ & $\begin{array}{l}3 \\
3 \\
* \\
3,6 \\
2,4 \\
2,3 \\
2,6 \\
3\end{array}$ & $\begin{array}{l}3 \\
3 \\
* \\
3,6 \\
6 \\
2 \\
* \\
*\end{array}$ & $\begin{array}{l}3 \\
2 \\
3 \\
\text { NT } \\
6 \\
2 \\
3,6 \\
*\end{array}$ & $\begin{array}{l}3,6 \\
2,3 \\
3 \\
\text { NT } \\
3 \\
2 \\
3 \\
3\end{array}$ & $\begin{array}{l}3,6 \\
2,3 \\
3 \\
\text { NT } \\
2 \\
2 \\
\text { NT } \\
\text { NT }\end{array}$ & $\begin{array}{l}* \\
3,5 \\
2 \\
\text { NT } \\
2,6 \\
2 \\
2 \\
\text { NT }\end{array}$ & $\begin{array}{l}* \\
2,5 \\
3,6 \\
\text { NT } \\
3 \\
2 \\
2 \\
*\end{array}$ & $\begin{array}{l}* \\
2,5 \\
3,6 \\
\text { NT } \\
2 \\
2,6 \\
\text { NT } \\
*\end{array}$ & $\begin{array}{l}* \\
2,5 \\
3,6 \\
\text { NT } \\
2 \\
2 \\
2 \\
*\end{array}$ & $\begin{array}{l}* \\
\text { NT } \\
3 \\
\text { NT } \\
6 \\
2 \\
6 \\
*\end{array}$ \\
\hline
\end{tabular}

No $U$ urealyticum recovered

NT $=$ not tested 
third of the participants in this study, as suggested by the continuous isolation of the same serotype. This supports the observations on men working in the Antarctic without exposure to heterosexual contact for up to 31 months. ${ }^{12} 13$ Most of the men in these studies had a persistent infection with $U$ urealyticum (non-typed), which could be eradicated for one year or more by a five-day course of tetracycline.

As in the study by Holmes, ${ }^{12}$ ureaplasmas were inconsistently recovered from some men, but in our survey it is not clear whether this was the result of occasional reinfection by their sexual partner or of a lack of sensitivity of the isolation methods used, which may not detect consistently fastidious strains of $U$ urealyticum.

The significantly higher geometric mean titre of $U$ urealyticum in patients with more than $70 \%$ of positive culture results compared with the other culture-positive men in this study possibly reflects the existence of a subgroup permanently heavily colonised with ureaplasmas and of a group harbouring fewer organisms, which cannot always be found by the isolation methods used. Similarly, the occasional detection of mixed infections in colonised patients may be explained by the occurrence of fastidious strains or of low numbers of $U$ urealyticum, although failure to detect mixed cultures may be due to the limited number of colonies which are stained in the IF test.

This study confirms Bowie's ${ }^{3}$ findings on the number of polymorphonuclear leucocytes in the firstvoided urine of men without urethritis. By similar methods, we never found $>12$ leucocytes per HPF in our specimens from healthy men whereas Bowie $^{3}$ considered $>15$ leucocytes per HPF as normal. In the absence of cultures for Neisseria gonorrhoeae and Chlamydia trachomatis this finding should be of value in the diagnosis of NGU, particularly in patients without urethral discharge.

Although a significant correlation exists between a first episode of chlamydia-negative NGU and a ureaplasmal titre of $>10^{3} \mathrm{ccu}$ in a first-voided urine sample, ${ }^{1}$ it is clear from our results that this is not a directly causal association. Except for patient 3 , none of the men studied developed NGU or related signs and symptoms in association with pronounced increases in ccu of $U$ urealyticum in their urine. Moreover, prevalence studies in more heterogeneous venereal disease clinic populations have failed to confirm Bowie's observation ${ }^{14}$ (Piot, unpublished data) in men experiencing a first episode of NGU. One man with presumably his first infection developed dysuria without a concomitant increase in urinary leucocytes. It is not clear whether the association of ureaplasmas with dysuria in this case is coincidental or causal. Our study group did not include enough men experiencing a first infection with $U$ urealyticum. Considering the high prevalence of $U$ urealyticum colonisation in sexually active people it is highly improbable that a simple primary infection with any type would cause NGU. Cohort studies to correlate the acquisition of ureaplasmas with NGU are extremely difficult to organise and would be severely handicapped by the lack of sensitive and specific serological tests.

It still remains possible that only certain serotypes or biotypes are pathogenic for the urethra, a hypothesis which has not been tested in a comprehensive study including cultures for chlamydia. This approach seems the most reasonable one at the moment, together with the search for a good experimental animal model as attempted by Bowie and coworkers. ${ }^{15}$

References

1. Bowie WR, Wang SP, Alexander ER, et al. Etiology of nongonococcal urethritis. Evidence for Chlamydia trachomatis and Ureaplasma urealyticum. J Clin Invest 1977; 59:735-42.

2. Shepard MC. Quantitative relationship of Ureaplasma urealyticum to the clinical course of nongonococcal urethritis in the human male. In: Bové JM, Duplan JF, eds. Les Mycoplasmes de l'Homme, des Animaux, des Végétaux, et des Insectes. Paris: Inserm, 1974:375-9.

3. Bowie WR. Comparison of Gram stain and first-voided urine sediment in the diagnosis of urethritis. Sex Transm Dis $1978 ; 5: 39-42$.

4. Coufalik ED, Taylor-Robinson D, Csonka GW. Treatment of nongonococcal urethritis with rifampicin as a means of defining the role of Ureaplasma urealyticum. Br J Vener Dis 1979; 55: 36-43.

5. Rodermund OE, Jänsch HH. Zur frage der bedeutung von mykoplasmen in der atiopathogenese nicht gonorrhoischer urethritiden des mannes. Hautarzt 1974; 25:597-602.

6. Taylor-Robinson D, Csonka GW, Prentice MJ. Chlamydial and ureaplasma-associated urethritis. Lancet $1977 ;$ i:903.

7. Robertson JA. Bromothymolblue broth: improved medium for detection of Ureaplasma urealyticum (T-strain mycoplasma). $J$ Clin Microbiol 1978; 7:127-32.

8. Shepard MC, Lunceford CD. A differential agar medium (A7) for identification of Ureaplasma urealyticum (human $T$ mycoplasma) in primary cultures of clinical material. J Clin Microbiol 1976; 3:613-25.

9. Shepard MC, Lunceford CD, Ford DK, et al. Ureaplasma urealyticum gen nov, sp nov: proposed nomenclature for the human T (T-strain) mycoplasma. Internat J Syst Bacteriol 1974;24:160-71.

10. Shepard MC, Lunceford CD. Serological typing of Ureaplasma urealyticum isolates from urethritis patients by an agar growth inhibition method. J Clin Microbiol 1978;8:566-74.

11. Piot P. Comparison of growth inhibition and immunofluorescence test in serotyping clinical isolates of Ureaplasma urealyticum. Br J Vener Dis 1977; 53: 186-9.

12. MacLeod AD, Furr PM, Taylor-Robinson D. Prolonged eradication of urogenital mycoplasmas after administration of tetracycline in men in the Antarctic. $B r J$ Vener Dis 1976;52:337-40.

13. Holmes MJ, Furr PM, Taylor-Robinson D. The persistence of mycoplasmas in the urogenital tract of men in the Antarctic. $J$ Hyg (Cambridge) 1974; 72:355-63.

14. Taylor-Robinson D, Evans RT, Coufalik ED, et al. Ureaplasma urealyticum and Mycoplasma hominis in chlamydial and non-chlamydial nongonococcal urethritis. $B r J$ Vener Dis 1979;55:30-35.

15. Bowie WR, Digiacomo, RF, Holmes KK, Gale JL. Genital inoculation of male Macaca fascicularis with Neisseria gonorrhoeae and Ureaplasma urealyticum. Br J Vener Dis 1978;54:235-8. 